\title{
An unique system of somatic embryogenesis in the tree fern Cyathea delgadii Sternb.: the importance of explant type, and physical and chemical factors
}

\author{
Anna Mikuła $^{1} \cdot$ Mariusz Pożoga $^{1} \cdot$ Małgorzata Grzyb $^{1} \cdot$ Jan J. Rybczyński $^{1}$
}

Received: 17 March 2015/Accepted: 13 August 2015/Published online: 21 August 2015

(C) The Author(s) 2015. This article is published with open access at Springerlink.com

\begin{abstract}
The effect of explant type (etiolation, age, length), physical (photoperiod, darkness) and chemical (sucrose and mineral salt concentrations) factors on somatic embryogenesis efficiency and sporophyte development in Cyathea delgadii was evaluated. Five-month-old cultures of sporophytes, which had developed 4-5 leaves, were used as a source of explants. The percentage response of stipes and the average number of somatic embryos were calculated after 2 months of culture. Etiolation of sporophytes used for culture initiation, was a critical factor in SE induction. Other factors studied significantly affected the production of somatic embryos. Optimum results were obtained when explants measuring $2.5 \mathrm{~mm}$ in length were excised from the youngest leaf of an etiolated sporophyte. Maximum SE efficiency (84.0 \% response in explants; 42.3 somatic embryos per explant) was obtained on halfstrength Murashige and Skoog medium supplemented with $1 \%$ sucrose, under photoperiod conditions. However, light stimulated two different morphogenetic responses in explant cells: SE and apospory. In darkness, the number of somatic embryos was reduced to 32.9 per explant, but this was the only morphogenetic response observed. The presence of light alone was sufficient for somatic embryos growing on plain agar gel to reach maturity, but further development stopped shortly thereafter. The presence of both light and sucrose was necessary for the development of an embryonic leaf and root. For further sporophyte growth, mineral salts were essential. The micropropagation
\end{abstract}

Anna Mikuła

amikula@obpan.pl

1 Polish Academy of Sciences Botanical Garden - Center for Biological Diversity Conservation in Powsin, Prawdziwka 2, 02-973 Warsaw, Poland system described here is the first investigation into factors responsible for SE in ferns.

Keywords Apospory - Etiolated explant · Hormone-free medium - Sucrose and mineral salt concentrations .

Sporophyte development

\begin{abstract}
Abbreviations
SE Somatic embryogenesis

1/2MS Medium containing half-strength Murashige and Skoog micro- and macro-nutrients
\end{abstract}

\section{Introduction}

Somatic embryogenesis (SE) is a valuable tool in plant biotechnology. This method of regeneration can be used for the large-scale clonal propagation, genetic improvement, and both short- and long-term storage of plant material. It also offers an attractive model system for studying molecular and cellular changes, as well as developmental mechanisms in plant embryogenesis (Yang and Zhang 2010; Mahdavi-Darvari et al. 2015). Somatic embryogenesis induction is a highly complicated, multi-factorial event involving endogenous hormones, and is mainly precipitated by exogenous plant growth regulators (Jiménez 2005). It is the preferred way of inducing embryogenic responses in vitro in most of the plant tissue culture systems examined to date (Gaj 2004). Moreover, in many species, the maturation of somatic embryos and their conversion into plants also require media supplemented with plant growth regulators (Filonova et al. 2000; Jiménez 2005). Only a few species possess sufficient developmental plasticity to modify their growth and produce somatic 
embryos in the absence of exogenous hormonal stimulation. In these systems, SE induction can be triggered by various stress treatments, such as osmotic shock, $\mathrm{pH}$, wounding or temporary immersion (Akula et al. 2000; Kamada et al. 1989, 1993; Smith and Krikorian 1990; Zavattieri et al. 2010). According to a survey of 124 protocols, hormone-free media were used to initiate the process in less than $7 \%$ (Gaj 2004). For some species, owing to habituation, secondary embryogenesis may require no growth regulators whatsoever (Raemakers et al. 1995). As well as plant growth regulators, the induction of SE during the in vitro culture of some species also requires certain physical factors, such as light, or chemical factors, such as nutrients and a suitable sucrose concentration in the medium (Gaj 2004). With respect to light conditions, either a photoperiod or darkness was required for the formation of somatic embryos in 49 and $44 \%$ of the 119 surveyed protocols (Gaj 2004), respectively. Studies on the effect of light on SE induction are few (Gaj 2004; Pinto et al. 2008). However, there are some reports on the influence of light on the development of angiosperm plantlets, for example Eucalyptus globulus Labill (Pinto et al. 2008), or on sporophyte development in fern species, such as Osmunda, Leptopteris, Todea, Adiantum (White 1971), as well as fern roots (Ambrožič-Dolinšek and Camloh 1997). The availability of sucrose (or other sugars) in the culture medium has been found to affect SE (Gaj 2004). This mainly resulted when sucrose concentration was raised (to 6.8 or $12 \%$ ), resulting in osmotic shock (Lou and Kako 1995; Karami et al. 2006; Nakagawa et al. 2001). However, in Linum usitatissimum, Cucumis melo and Passiflora spp., no more than $3 \%$ sucrose resulted in maximum SE induction (Cunha and Fernandes-Ferreira 1999; Gray et al. 1993; Ferreira et al. 2015). The capacity for SE induction in plant cells largely depends upon the source and type of the initial explant as well as the developmental stage of its tissues. The young and rapidly growing tissues of the immature or mature zygotic embryos, and their axes or parts of seedlings, are considered to be the most effective explants for the induction of most gymnosperm and angiosperm embryogenic cultures (Raemakers et al. 1995; Chen and Chang 2002; Gaj 2004; Yan-Lin and Soon-Kwan 2012). Some studies have shown that explant length also affects success during SE induction (Takamura and Tanaka 1996; Gow et al. 2010).

Evidence from previous reports indicate that plant growth regulators (Menéndez et al. 2006; Parajuli and Joshi 2014), nutrients (Fernández et al. 1999; Kuriyama et al. 2004; Moura et al. 2012), sugar (Ambrósio and de Melo 2004; Fernández et al. 1996; Hirsch 1975; Materi and Cumming 1991), and other physical and chemical factors affect the induction, growth and development of fern sporophytes resulting from both sexual and asexual (by apogamy, adventitious buds) means of reproduction (Fernández and Revilla 2003). Morphogenesis in ferns can also be induced by homogenization or mechanical disruption of gametophytes and sporophytes (Fernández et al. 1999; Somer et al. 2010). For many fern species propagated under in vitro conditions, the production of gametophytes by sporophyte somatic cells (apospory) is frequently induced (Cordle et al. 2011). In vitro propagation of this kind has been demonstrated for both herbaceous fern species and tree ferns by Bharati et al. (2013) and Rybczyński and Mikuła (2011), respectively. Despite the application of in vitro culture methods to fern propagation, except for an embryo-like structure described for the epiphytic fern $\mathrm{Mi}$ crogramma vacciniifolia (Hirsch 1976), until our recent discovery, the capacity to undergo SE had never been reported for monilophytes (Mikuła et al. 2015). Our study showed that it is easy to induce this phenomenon in the tree fern $C$. delgadii. It is straightforward to obtain somatic embryos from the stipes of juvenile sporophytes grown in the dark in the absence of exogenous plant growth regulators, even without sub-culturing during long-term culture (Mikuła et al. 2015). We would now like to broaden our knowledge to include investigation of the basic physical and chemical factors that affect in vitro culture and how these may influence the course of SE. The aim of our investigation is to evaluate the effect of explant type (etiolation, age, length), and physical (photoperiod, darkness) and chemical (sucrose and mineral salt concentrations) factors on SE efficiency and sporophyte development in the tree fern C. delgadii.

\section{Materials and methods}

\section{Plant material}

Primary embryogenic culture of $C$. delgadii was established following the procedure described by Mikuła et al. (2015). In all experiments presented here, 5-month-old cultures of somatic embryo-derived sporophytes were used as a source of explants. Sporophytes were cultured in jars on medium containing half-strength Murashige and Skoog's (1962) (MS) macro- and micro-nutrients and a full complement of vitamins (1/2MS), $2 \%$ (w/v) sucrose, and solidified using $0.7 \%$ plant agar (Duchefa Biochemie). The $\mathrm{pH}$ was adjusted to 5.8 before autoclaving. Cultures were maintained in constant darkness or under $16 / 8 \mathrm{~h}$ photoperiod conditions, in a climatic chamber at $+24 \pm 1{ }^{\circ} \mathrm{C}$, and at a relative humidity of $35-55 \%$. Stipes of sporophytes that had developed 4-5 leaves, were used for the study. 


\section{Explant type}

Firstly, the effect of etiolation of sporophytes on the embryogenic potential of explants subsequently derived from them was examined. The proximal part of stipes of non-etiolated (Fig. 1a) and etiolated (Fig. 1b) sporophytes were excised (2.5 $\mathrm{mm}$ in length) and used as explants.
Cultures were maintained on 1/2MS medium supplemented with $2 \%(\mathrm{w} / \mathrm{v})$ sucrose, in the presence or absence of light, in a climatic chamber as described above.

In order to determine whether age of fronds and size of explants influence embryogenic potential, stipe explants measuring 1.5, 2.5 and $5.0 \mathrm{~mm}$ in length were excised from the first, second and third frond of etiolated sporophytes
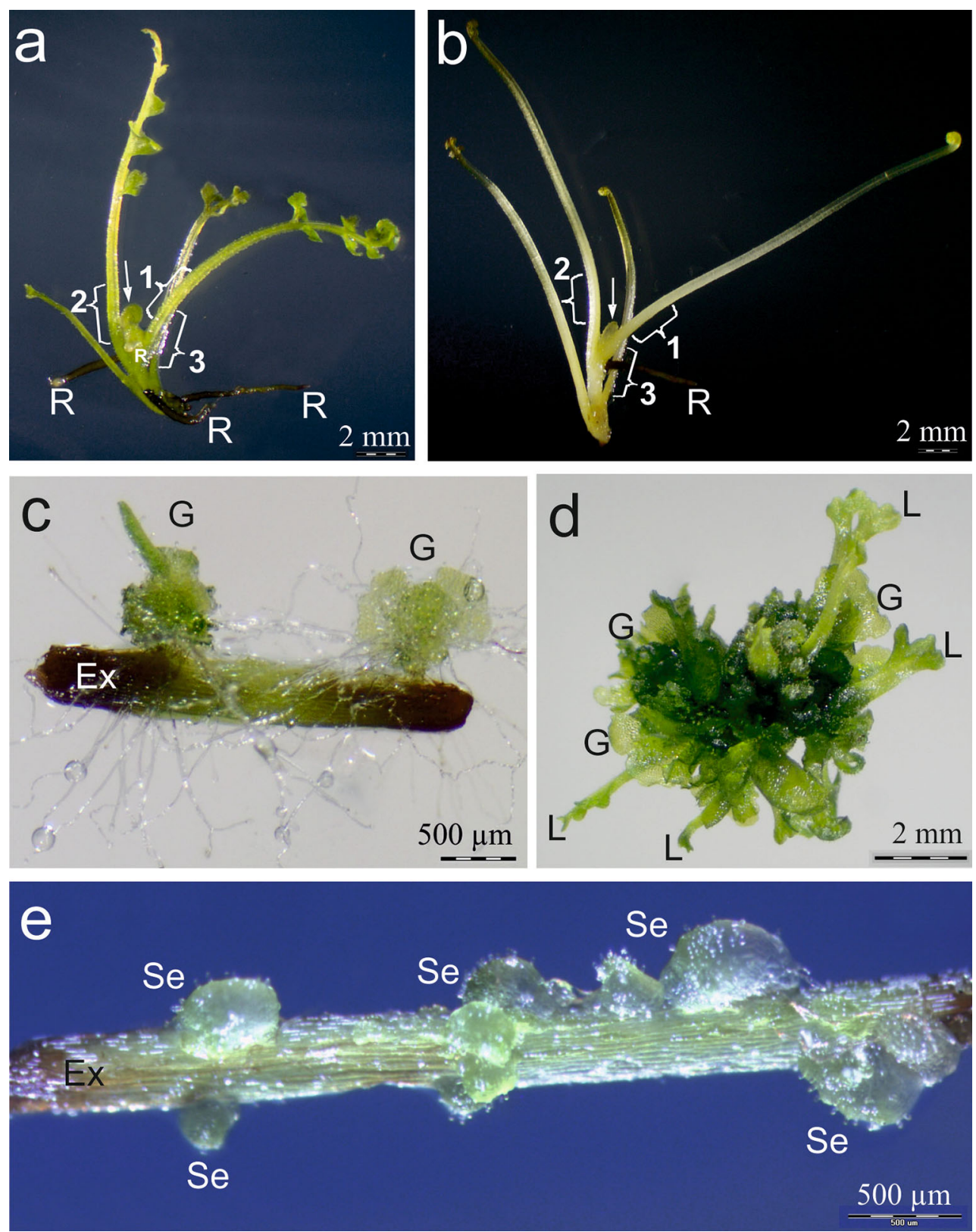

Fig. 1 The origin (a, b) and morphogenetic response (c-e) of Cyathea delgadii stipe explants used in culture initiation. Stipe explants were excised from the base of the first (1), second (2) and third (3) frond of somatic embryo-derived sporophytes cultured a under photoperiod conditions or $\mathbf{b}$ in darkness. c Aposporous gametophytes developing on a non-etiolated explant after 8 weeks of culture under photoperiod conditions. d Somatic embryo-derived juvenile sporophytes and gametophytes developing on an etiolated explant after 8 weeks of culture under photoperiod conditions. e Numerous somatic embryos developed directly on the surface of etiolated explants, in constant darkness, after 4 weeks of culture. Arrow, primordium of the youngest leaf. Ex explants, $G$ gametophyte, $L$ leaf, $R$ root, $S e$ somatic embryo, 1, 2, 3, first, second and third frond 
(Fig. 1b). The cultures were maintained on 1/2MS medium supplemented with $2 \%(\mathrm{w} / \mathrm{v})$ sucrose, in constant darkness.

\section{Physical and chemical factors}

In order to determine the influence of light conditions and the mineral salt concentration of the medium on SE efficiency, $2.5 \mathrm{~mm}$ long etiolated explants derived from the first frond were used. Explants of the same length, but derived in equal quantities from the first, second and third fronds, were used to investigate the effect of sucrose concentration. For these types of explants, the effectiveness of various concentrations of macro- and micro-nutrient salts (MS; 1/2MS; 1/4MS; $1 / 8 \mathrm{MS}$ ) and sucrose concentration (from 1 to $5 \%$ ) were evaluated. As a control, plain agar gel was used. Cultures were kept either at a $16 / 8 \mathrm{~h}$ photoperiod and a light intensity of $50 \mu \mathrm{M} \mathrm{m}^{-2} \mathrm{~s}^{-1}$ or in constant darkness.

\section{Somatic embryogenesis evaluation and statistical analysis}

The percentage response of explants and the number of somatic embryos per responding explant were calculated following 2 months of culture. In order to evaluate the effect of initial sporophytes on the morphogenetic response of stipe explants, 32 explants were examined, and the experiments repeated twice. In total, 64 explants per treatment were used. All remaining experiments were repeated 3 times, each repeat consisting of 3 Petri dishes of 16 explants each. In total, 144 explants per treatment were used.

Results were analysed by means of one- or two-way ANOVA analysis of variance and Fisher's least significant difference (LSD) procedure using Statgraphics Plus software. Significance was set at the 0.05 level. Results were expressed as the mean $\pm \mathrm{SD}$ based on three independent experiments.

\section{Results}

\section{Influence of etiolation on the morphogenetic response}

Different light conditions during the development of juvenile sporophytes of $C$. delgadii modified the morphogenetic response of the stipe explants derived from them. Moreover, by using constant darkness during somatic embryo induction, initial explants could be successfully directed towards SE. Table 1 summarizes the effect of sporophyte etiolation and light conditions during initial explant culture on their morphogenetic response. The nonetiolated explants, excised from sporophytes developed under 16/8 h photoperiod conditions (Fig. 1a), were incapable of forming somatic embryos (Table 1). However, 11.2 and $7.2 \%$ of those explants produced aposporous gametophytes (Fig. 1c) under photoperiod conditions and in the dark, respectively. If the explants were excised from etiolated sporophytes (Fig. 1b), their morphogenetic response was found to depend on the light conditions used for their culture. Under photoperiod conditions, 38.2 and $29.6 \%$, respectively, of the etiolated explants were capable of producing gametophytes and somatic embryos (Fig. 1d). Both types of structure developed directly from cells of stipe explants. In constant darkness, only somatic embryos were observed to develop on the surface of explants (Fig. 1e). Some $64.6 \%$ of explants underwent SE (Table 1).

\section{Influence of explant type on SE efficiency}

The effect of three different lengths of explants, as well as age of frond from which the explants were taken on SE induction, are compared in Table 2. The results showed no significant differences with respect to the influence of frond age on the average number of somatic embryos per responding explant. However, this factor significantly affected the percentage of responding explants. The response of stipe explants derived from the first frond was approximately twofold higher $(44.2 \%)$ than the others (ca. $27 \%$ ). The process of SE in explants derived from the second and third frond was statistically just as efficient (Table 2).

Explant length had a significant $(P<0.001)$ effect on the number of somatic embryos per responding explant, but it did not significantly affect the percentage explants showing SE. Explants some $2.5 \mathrm{~mm}$ long produced the greatest number of somatic embryos, totaling more than 19 per explant. There were no significant differences in the average number of somatic embryos between explants measuring 1.5 and $5 \mathrm{~mm}$ length. Except for the longest explant (5 $\mathrm{mm}$ in length) derived from the oldest studied frond (no. 3), and which produced only 7.9 somatic embryos per responding explant, the response of the other explants ranged from 10.8 to 19.7 embryos. There was no statistically significant interaction between the length of explants and age of frond from which the explants were taken (Table 2).

\section{Influence of physical and chemical factors on SE efficiency}

Both the frequency of explants forming somatic embryos and the efficiency of somatic embryo production were 
Table 1 Effect of sporophyte etiolation and light conditions during explant culture on the morphogenetic response of stipe explants

\begin{tabular}{llll}
\hline Initial sporophytes/explants & $\begin{array}{l}\text { Light conditions for } \\
\text { initial explant culture }\end{array}$ & \% explants with & \\
\cline { 3 - 4 } & & Gametophytes & Somatic embryos \\
\hline Non-etiolated & Photoperiod & $11.2 \pm 8.4 \mathrm{~b}$ & $0 \mathrm{c}$ \\
& Darkness & $7.2 \pm 6.7 \mathrm{~b}$ & $0 \mathrm{c}$ \\
Etiolated & Photoperiod & $38.2 \pm 7.3 \mathrm{a}$ & $29.6 \pm 22.5 \mathrm{~b}$ \\
& Darkness & $0 \mathrm{c}$ & $64.6 \pm 15.9 \mathrm{a}$ \\
\hline
\end{tabular}

$\pm \mathrm{SD}$

Table 2 The influence of explant type on percentage of explants showing SE (\%) and number of somatic embryos per responding explant (No.)

\begin{tabular}{|c|c|c|c|c|c|c|}
\hline \multirow[t]{2}{*}{ Explant length (mm) } & \multirow[t]{2}{*}{ SE efficiency } & \multicolumn{5}{|l|}{ Age of frond ${ }^{*}$} \\
\hline & & $1 \mathrm{st}$ & 2nd & $3 \mathrm{rd}$ & Mean & \\
\hline \multirow[t]{2}{*}{1.5} & $\%$ & $47.9 \pm 11.7 \mathrm{a}$ & $26.7 \pm 16.2 b c$ & $19.4 \pm 12.7 \mathrm{c}$ & $31.3 \mathrm{~A}$ & \\
\hline & No. & $11.9 \pm 12.1 \mathrm{bcd}$ & $12.7 \pm 12.6 \mathrm{bcd}$ & $17.1 \pm 14.9 \mathrm{abc}$ & & $13.2 \mathrm{~B}$ \\
\hline \multirow[t]{2}{*}{2.5} & $\%$ & $46.5 \pm 15.0 \mathrm{a}$ & $29.2 \pm 14.0 \mathrm{bc}$ & $25.0 \pm 12.5 \mathrm{bc}$ & $33.6 \mathrm{~A}$ & \\
\hline & No. & $19.4 \pm 17.2 \mathrm{a}$ & $17.3 \pm 15.5 a b$ & $19.7 \pm 16.0 \mathrm{a}$ & & $19.0 \mathrm{~A}$ \\
\hline \multirow[t]{2}{*}{5.0} & $\%$ & $38.2 \pm 20.8 \mathrm{ab}$ & $27.8 \pm 18.0 \mathrm{bc}$ & $37.5 \pm 15.3 \mathrm{ab}$ & $27.3 \mathrm{~A}$ & \\
\hline & No. & $10.8 \pm 15.8 \mathrm{~cd}$ & $11.8 \pm 15.4 \mathrm{bcd}$ & $7.9 \pm 8.7 \mathrm{~d}$ & & $10.0 \mathrm{~B}$ \\
\hline \multirow[t]{2}{*}{ Mean } & $\%$ & $44.2 \mathrm{~A}$ & $27.9 \mathrm{~B}$ & $27.3 \mathrm{~B}$ & & \\
\hline & No. & $14.1 \mathrm{~A}$ & $14.0 \mathrm{~A}$ & $14.9 \mathrm{~A}$ & & \\
\hline
\end{tabular}

Darkness; medium $1 / 2 \mathrm{MS}$ with $2 \%$ sucrose

Within each column, means $( \pm \mathrm{SD})$ followed by different letters differ significantly at $p \leq 0.05$ according to Fisher's least significant difference (LSD) test

* 1, 2, 3, stipe explants derived from the first, second and third frond, respectively (see Fig. 1b)

significantly $(P<0.001)$ affected by the concentration of micro- and macro-nutrients in the MS medium, with the greatest percentage (more than $50 \%$ ) and number (more than 20) being achieved on the $1 / 2 \mathrm{MS}$ medium (Table 3 ). An increase or reduction in salt concentration significantly reduced the efficiency of SE.
Regarding the influence of the light conditions on SE efficiency, no significant differences were found between cultures maintained under $16 / 8 \mathrm{~h}$ photoperiod conditions and those subjected to constant darkness. However, the greatest percentage of responding explants (i.e. $53.5 \%$ ) and the greatest number of somatic embryos per explant
Table 3 Influence of light conditions and mineral salt concentration using Murashige and Skoog's medium supplemented with $2 \%(\mathrm{w} / \mathrm{v})$ sucrose on percentage explants showing SE (\%) and the number of somatic embryos per responding explant (No.)

\begin{tabular}{|c|c|c|c|c|c|}
\hline \multirow[t]{2}{*}{ Mineral salt concentration } & \multirow[t]{2}{*}{ SE efficiency } & \multicolumn{4}{|l|}{ Light conditions } \\
\hline & & Photoperiod & Darkness & Mean & \\
\hline \multirow[t]{2}{*}{ MS } & $\%$ & $9.0 \pm 5.5 \mathrm{ef}$ & $15.3 \pm 8.9 \mathrm{def}$ & $12.2 \mathrm{D}$ & \\
\hline & No. & $7.2 \pm 13.7 \mathrm{c}$ & $5.8 \pm 9.0 \mathrm{c}$ & & $6.6 \mathrm{~B}$ \\
\hline \multirow[t]{2}{*}{$1 / 2 \mathrm{MS}$} & $\%$ & $53.5 \pm 23.4 \mathrm{a}$ & $48.6 \pm 17.6 \mathrm{a}$ & $51.0 \mathrm{~A}$ & \\
\hline & No. & $23.8 \pm 19.6 \mathrm{a}$ & $17.5 \pm 15.3 \mathrm{~b}$ & & $20.7 \mathrm{~A}$ \\
\hline \multirow[t]{2}{*}{ 1/4MS } & $\%$ & $36.1 \pm 13.2 \mathrm{~b}$ & $28.5 \pm 8.9 \mathrm{bc}$ & $32.3 \mathrm{~B}$ & \\
\hline & No. & $8.4 \pm 10.7 \mathrm{c}$ & $7.2 \pm 8.7 \mathrm{c}$ & & $7.7 \mathrm{~B}$ \\
\hline \multirow[t]{2}{*}{ 1/8MS } & $\%$ & $18.1 \pm 16.4 \mathrm{cde}$ & $25.7 \pm 10.6 \mathrm{bcd}$ & $21.9 \mathrm{C}$ & \\
\hline & No. & $4.5 \pm 5.0 \mathrm{c}$ & $7.6 \pm 15.7 \mathrm{c}$ & & $6.6 \mathrm{~B}$ \\
\hline \multirow[t]{2}{*}{$2 \%$ sucrose solution } & $\%$ & $3.5 \pm 3.3 \mathrm{f}$ & $3.5 \pm 4.5 \mathrm{f}$ & $3.5 \mathrm{E}$ & \\
\hline & No. & $2.4 \pm 1.1 \mathrm{c}$ & $1.8 \pm 1.3 \mathrm{c}$ & & $2.1 \mathrm{~B}$ \\
\hline \multirow[t]{2}{*}{ Mean } & $\%$ & $24.0 \mathrm{~A}$ & $24.3 \mathrm{~A}$ & & \\
\hline & No. & $10.0 \mathrm{~A}$ & $7.5 \mathrm{~A}$ & & \\
\hline
\end{tabular}

Within each column, means $( \pm \mathrm{SD})$ followed by different letters differ significantly at $p \leq 0.05$ according to Fisher's least significant difference (LSD) test 
(i.e. 23.8) were achieved in the presence of light. These values were somewhat reduced when cultures were grown on the same medium, but in the dark. There was no statistically significant interaction between mineral salt concentration and light conditions (Table 3 ).

The effects of various sucrose concentrations correlated with light conditions on the induction of SE are shown in Table 4. Sucrose concentration had a statistically significant $(P<0.001)$ effect on the ability of stipe explants to undergo SE. Of the five sucrose concentrations (from 1 to $5 \%$ ) evaluated, $1 \%$ sucrose showed the best results both in terms of percentage explants showing SE (average $75.3 \%)$ and the average number of somatic embryos (37.8) produced per explant. Similarly, $3 \%$ sucrose also gave good results for $\mathrm{SE}$ induction of $C$. delgadii. On that medium, $53.5 \%$ explants produced almost 32 somatic embryos per responding explant. A sucrose concentration of greater than $3 \%$ in the induction $1 / 2 \mathrm{MS}$ medium significantly reduced SE efficiency.

It is worth emphasizing that between 3.5 and $13.9 \%$ stipe explants were capable of somatic embryo production on plain agar gel both supplemented with (Table 3) and minus sucrose (Table 4).

Light, in the presence of various sucrose concentrations, significantly $(P<0.001)$ affected the capacity of explants for $\mathrm{SE}$ and the number of somatic embryos produced per responding explant (Table 4). Under photoperiod conditions, at optimal sucrose concentration (1\%), $84.0 \%$ of responding explants were able to produce as many as 42.3 somatic embryos each. Conversely, in darkness, these results were 66.7 and $32.9 \%$, respectively. Analysis of variance demonstrated statistically significant interaction between sucrose concentration and light conditions for both determined parameters of SE efficiency (Table 4).

\section{Effect of physical and chemical factors on somatic embryo and sporophyte development}

The development of somatic embryos induced in the dark on plain agar gel stopped at the early embryonic leaf stage (Fig. 2a). Under photoperiod conditions, somatic embryos reached the late embryonic leaf stage, beyond which their development became interrupted (Fig. 2b). Enrichment of the agar gel with $2 \%$ sucrose allowed the embryos to complete their development, resulting in leaf elongation, blade expansion and root formation (Fig. 2c).

Trends in the development of somatic embryo-derived sporophytes under light conditions and salt concentration are shown in Fig. 3. The study showed that light has a pronounced effect on the development of sporophytes. In constant darkness, the blades of young sporophytes remained at the crosier stage (Fig. 3a, b, c). The frond was partly yellowish-green towards the apex. The stipe of the frond was cream in color. Under photoperiod conditions, the blades of the fronds developed, and the entire sporophytes were green in color (Fig. 3d, e, f).
Table 4 The influence of light conditions and sucrose concentration on percentage explants showing SE $(\%)$ and the number of somatic embryos produced per responding explant (No.)

\begin{tabular}{|c|c|c|c|c|c|}
\hline \multirow[t]{2}{*}{ Sucrose concentration } & \multirow[t]{2}{*}{ SE efficiency } & \multicolumn{4}{|l|}{ Light conditions } \\
\hline & & Photoperiod & Darkness & Mean & \\
\hline \multirow[t]{2}{*}{$5 \%$} & $\%$ & $41.7 \pm 20.5 \mathrm{c}$ & $16.7 \pm 10.4$ ef & $29.2 \mathrm{C}$ & \\
\hline & No. & $14.4 \pm 9.8 \mathrm{f}$ & $9.6 \pm 8.8 \mathrm{fgh}$ & & $11.8 \mathrm{D}$ \\
\hline \multirow[t]{2}{*}{$4 \%$} & $\%$ & $33.3 \pm 11.3 \mathrm{~cd}$ & $25.7 \pm 21.1 \mathrm{de}$ & $29.5 \mathrm{C}$ & \\
\hline & No. & $14.0 \pm 12.8 \mathrm{fg}$ & $15.1 \pm 13.8 \mathrm{ef}$ & & $14.2 \mathrm{D}$ \\
\hline \multirow[t]{2}{*}{$3 \%$} & $\%$ & $63.2 \pm 29.8 \mathrm{~b}$ & $43.8 \pm 18.5 \mathrm{c}$ & $53.5 \mathrm{~B}$ & \\
\hline & No. & $37.7 \pm 23.4 \mathrm{ab}$ & $24.6 \pm 20.2 \mathrm{~d}$ & & $31.8 \mathrm{~B}$ \\
\hline \multirow[t]{2}{*}{$2 \%$} & $\%$ & $68.8 \pm 14.0 \mathrm{~b}$ & $21.5 \pm 15.0 \mathrm{de}$ & $45.1 \mathrm{~B}$ & \\
\hline & No. & $22.0 \pm 17.8 \mathrm{de}$ & $25.1 \pm 24.3 \mathrm{cde}$ & & $21.1 \mathrm{C}$ \\
\hline \multirow[t]{2}{*}{$1 \%$} & $\%$ & $84.0 \pm 16.6 \mathrm{a}$ & $66.7 \pm 22.1 \mathrm{~b}$ & $75.3 \mathrm{~A}$ & \\
\hline & No. & $42.3 \pm 32.8 \mathrm{a}$ & $32.9 \pm 22.4 \mathrm{bc}$ & & $37.8 \mathrm{~A}$ \\
\hline \multirow[t]{2}{*}{$0 \%$} & $\%$ & $1.4 \pm 2.8 \mathrm{~g}$ & $0.0 \mathrm{~g}$ & $0.7 \mathrm{D}$ & \\
\hline & No. & $1.0 \pm 0.0 \mathrm{~h}$ & $0.0 \mathrm{~h}$ & & $0.4 \mathrm{E}$ \\
\hline \multirow[t]{2}{*}{ Plain agar gel $0 \%$} & $\%$ & $13.9 \pm 11.2 \mathrm{efg}$ & $5.6 \pm 6.6 \mathrm{fg}$ & $9.7 \mathrm{D}$ & \\
\hline & No. & $1.2 \pm 0.4 \mathrm{~h}$ & $1.0 \pm 0.0 \mathrm{~h}$ & & $0.2 \mathrm{E}$ \\
\hline \multirow[t]{2}{*}{ Mean } & $\%$ & $43.8 \mathrm{~A}$ & $25.7 \mathrm{~B}$ & & \\
\hline & No. & $19.4 \mathrm{~A}$ & $13.2 \mathrm{~B}$ & & \\
\hline
\end{tabular}

Medium: $1 / 2 \mathrm{MS}$ or plain $0.7 \%$ agar gel plus (1-5\%) or minus $(0 \%)$ sucrose

Within each column, means $( \pm \mathrm{SD})$ followed by different letters differ significantly at $p \leq 0.05$ according to Fisher's least significant difference (LSD) test 


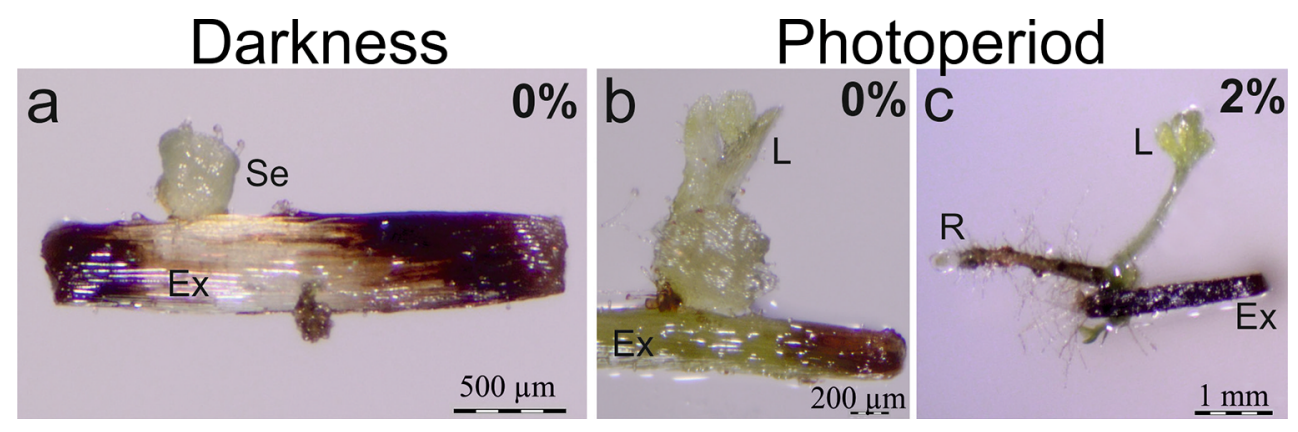

Fig. 2 Effect of photoperiod conditions and $2 \%$ sucrose on development of somatic embryos initiated on explants kept on plain agar gel, 2 months after culture initiation. a Somatic embryo growth stopped at the early embryonic leaf stage when grown in darkness. b A somatic embryo which reached the late embryonic leaf stage under photoperiod conditions. c A somatic embryo-derived sporophyte with the first embryonic leaf and root developing in the presence of light and sucrose. Ex explant, $L$ leaf, $R$ root, $S e$ somatic embryo
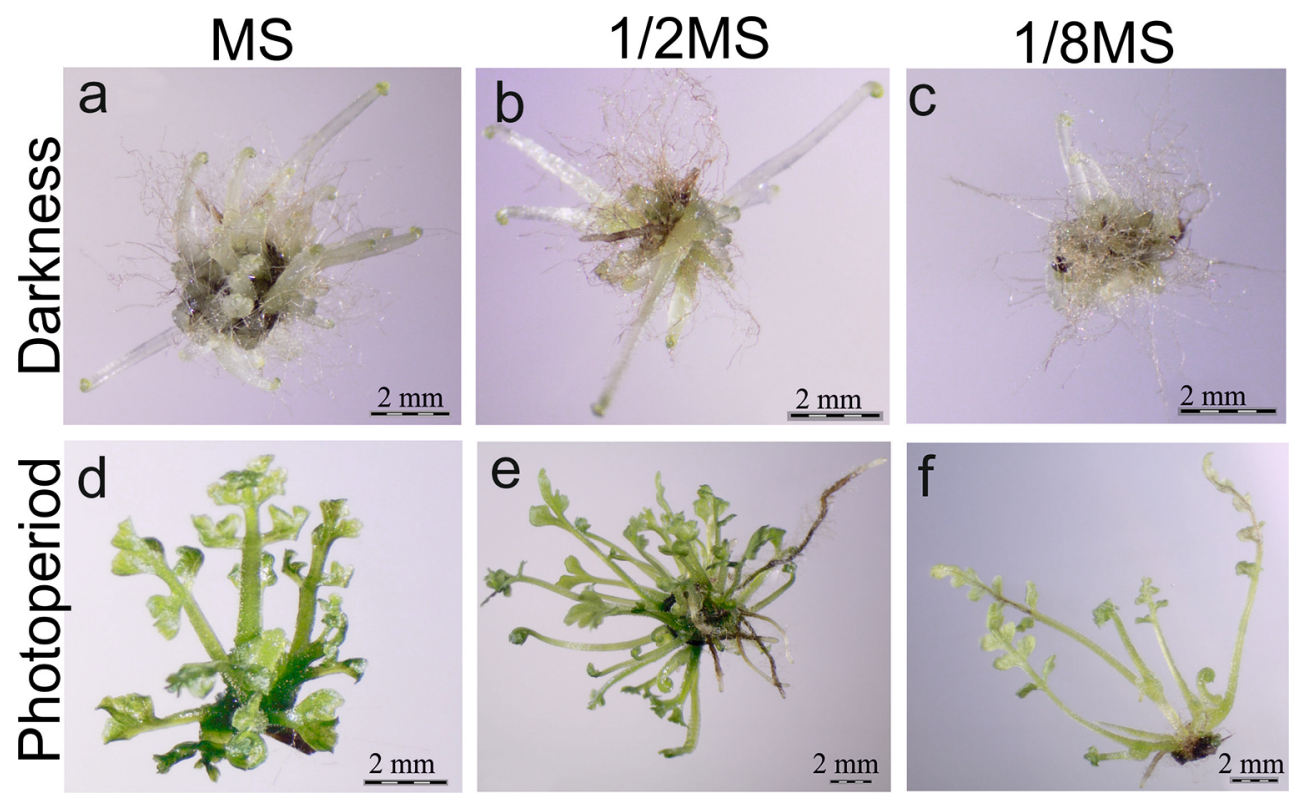

Fig. 3 General view of the effect of light conditions and salt concentration using MS medium supplemented with $2 \%$ sucrose on the development of somatic embryo-derived sporophytes after 2 months of induction culture. a, b, $\mathbf{c}$ In darkness, the sporophytes remained at the crosier stage. Reduction in salt concentration of the

The response to various concentrations of micro- and macro-nutrients in the MS medium was dependent on light conditions. In darkness, the length of the fronds was reduced at low salt concentrations. Moreover, the development of somatic embryos was inhibited or delayed (Fig. 3c). Conversely, in the presence of light, reduction in salt concentration stimulated frond elongation (Fig. 3d, e, f). Thus, the longest fronds occurred on plants growing on 1/8MS medium (Fig. 3f). The shortest and thickest fronds of $C$. delgadii were produced on full strength MS medium (Fig. 3d).

Changes in the development of sporophytes following 2 months of culture in the presence of various sucrose concentrations are shown in Fig. 4. Light conditions and initial medium inhibited elongation of young sporophytes. d, e, $\mathbf{f}$ Under photoperiod conditions, the blades were seen to have developed. Reduction of salt concentration stimulated frond elongation

sucrose concentrations clearly had a significant effect on the appearance of both somatic embryos and sporophytes, and their capacity to form roots. Regardless of light conditions, root formation was inhibited when somatic embryos were induced in the presence of $1 \%$ sucrose (Fig. 4a, b). The earliest-formed roots were produced when somatic embryos were induced on 1/2MS containing $2 \%$ sucrose. However, in darkness, the roots remained at the primordial phase (Fig. 4c), whereas light stimulated their elongation (Fig. 4d). A concentration of $3 \%$ or more sucrose strongly stimulated root production, but simultaneously inhibited frond growth (Fig. 4e-j). Regardless of these morphological changes, light promoted blade development. 


\section{Darkness}
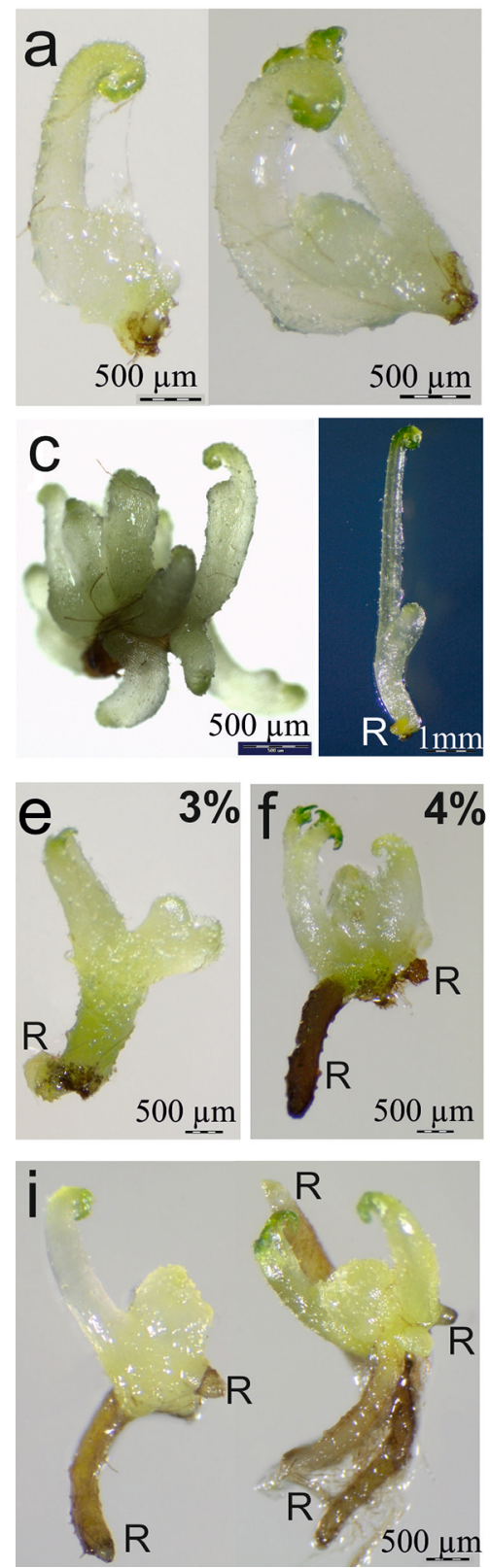

Fig. 4 Development of somatic embryo-derived sporophytes of Cyathea delgadii cultured in darkness or under photoperiod conditions, in the presence of various sucrose concentrations; 1/2MS, 2 months after culture initiation. a, b Young sporophytes lacking roots, with one or two developing fronds (1\% sucrose). c Clump of somatic embryos induced and developed in darkness, with root primordium at base of the

\section{Discussion}

\section{Factors controlling induction of somatic embryogenesis}

In the present study, we describe a unique system of SE in the tree fern $C$. delgadii which is completely independent

\section{Photoperiod}
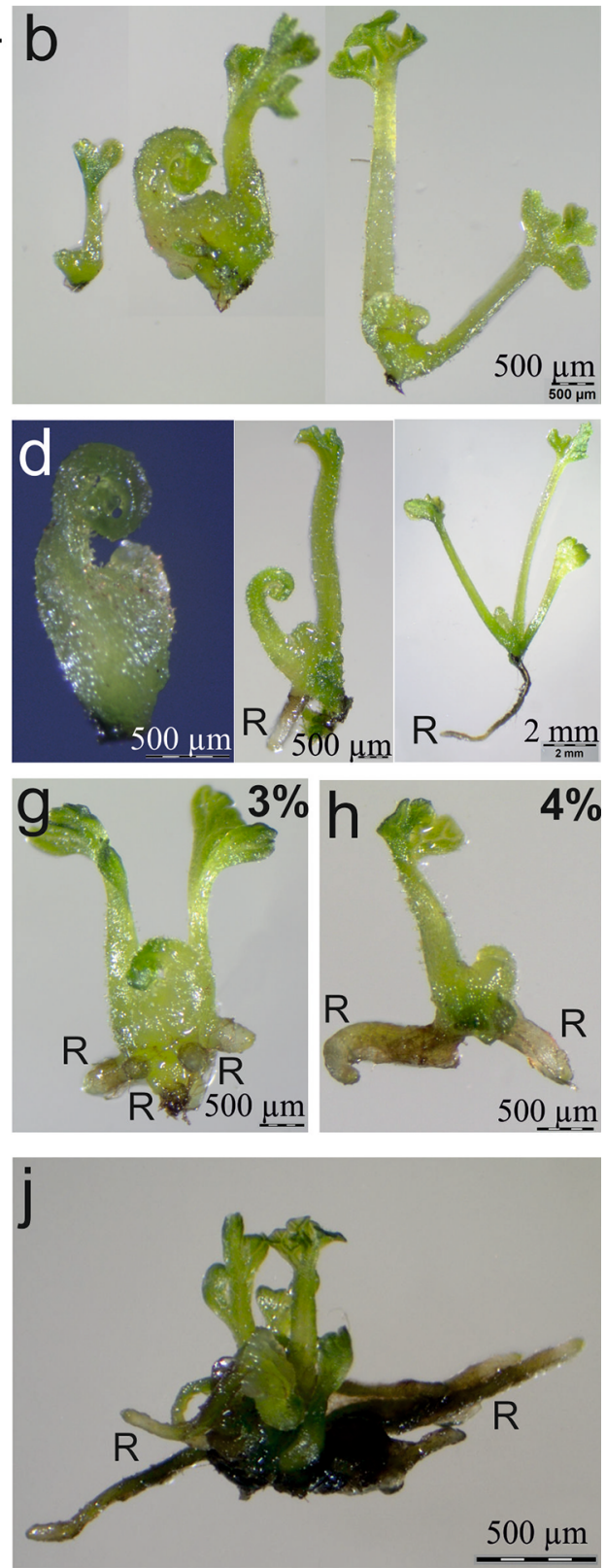

embryonic leaf ( $2 \%$ sucrose). d Somatic embryo in late embryogenic leaf stage and young sporophytes with two or three fronds and one root, developed under photoperiod conditions. e When the medium is supplemented with $3 \%$ or more sucrose, the leaves become shorter and thicker $\mathbf{f}, \mathbf{g}, \mathbf{h}, \mathbf{i}, \mathbf{j}$ Mass root production, root elongation and inhibition of frond growth occurred at higher (3-5\%) sucrose concentrations

of exogenous plant growth regulators. Here, the etiolation of sporophytes used as a source of initial explants is found to be the critical factor controlling induction of SE. In fern studies, it was shown that two non-antagonistic events can appear simultaneously on the same explants, i.e. the development of aposporous gametophytes and the development of outgrowths (known also as buds, globular 
bodies, sporophytes, shoots) (Somer et al. 2010; Bui et al. 2012). Our study showed that the cells of both non-etiolated and etiolated explants of $C$. delgadii were capable of morphogenetic response, but that only etiolated explants formed somatic embryos. According to Bharati et al. (2013), there are no other reports on the use of etiolated fern explants to initiate in vitro cultures. Moreover, for the majority of ferns, initial plant material was restricted to spore-derived gametophytes, whereas explants derived from other sources were much less common (Rybczyński and Mikuła 2011; Bharati et al. 2013). This may be why SE in cryptogamic plants is still not as well-known as that of spermatophytes. In some herbaceous ferns, e.g. Matteuccia struthiopteris and Platycerium bifurcatum, the rhizomederived meristems or juvenile leaves of in vitro-grown sporophytes were used, and efficient multiplication of adventitious buds or globular bodies was achieved (Dykeman and Cumming 1985; Liao and Wu 2011). The epiphytic fern Microgramma vacciniifolia seems to be an exception to this rule. On 2-5 mm-long juvenile leaves of this species, which were excised from cultured juvenile plants, Hirsch (1976) obtained globular outgrowths which she called 'embryo-like structures'. Subsequently, these structures developed small leaves and occasionally rhizoids. They were quite similar to the somatic embryos described for $C$. delgadii (Mikuła et al. 2015). This may indicate that the age of initial plants used for fern culture initiation is the second crucial factor stimulating SE. The discovery of that factor, together with the effect of the length of explants, make an important contribution to the effective production of somatic embryos in $C$. delgadii. According to Gow et al. (2010), $1 \mathrm{~cm}$ long leaf explants of the orchid Phalaenopsis amabilis excised from the youngest donor plants showed better embryogenic response than those measuring 1.5 and $2 \mathrm{~cm}$ in length, which were incapable of somatic embryo production. Similarly, Nhut et al. (2001) proved that short explants are better for shoot formation. Data obtained here confirm that the use of stipe explants derived from the first frond (i.e. the youngest frond), is better for SE induction in $C$. delgadii. The embryogenic response of both $1.5 \mathrm{~mm}$ and $2.5 \mathrm{~mm}$ long explants reached $50 \%$, but the number of somatic embryos formed by each was different, i.e. about 12 and 19 , respectively. Senescing brown-colored cells on the cut ends of the smallest explants strongly reduced the number of epidermal cells which can give rise to somatic embryos. The epidermal single cell origin of $C$. delgadii somatic embryos has previously been demonstrated (Mikuła et al. 2015).

The system of SE induction found in $C$. delgadii by far excels the well-known schemes described for seed plants (Gaj 2004; Raemakers et al. 1995; Yan-Lin and SoonKwan 2012). It occurs independently of plant growth regulators, and the other commonly used stress-inducing factors summarized by Zavattieri et al. (2010), as well as mechanical disruption (Mikuła et al. 2015). Our previous studies showed that differences in efficiency of SE induction in both intact and wounded somatic embryo-derived explants was insignificant, with $71-85 \%$ of responding explants each producing an average of 12 somatic embryos (Mikuła et al. 2015). The present paper demonstrates that at least three external factors, including light, sucrose and mineral salt concentrations, are able to modify the effectiveness of SE.

Light is a crucial factor in stimulating regeneration in cryptogamic plants. It was shown that light promotes apogamic reproduction and gametophyte formation in both ferns and mosses (Whittier and Pratt 1971; Martin et al. 2006; Rashid 2009). Data obtained here show that light also plays an important role in SE in C. delgadii. Light stimulates the process, but its presence is not essential for the formation of somatic embryos. Both dark- and lightmaintained etiolated explants were able to produce somatic embryos, but in the presence of light, the efficiency of SE was greater. In the dark, there is little growth of gametophytes, even on media enriched with sucrose. Furthermore, dark-grown gametophytes do not form apogamous structures (Whittier and Pratt 1971; Raghavan 1989). Our results showed that in the absence of light during culture, apospory in initial explants was inhibited, so that the epidermal cells of stipes were able only to form somatic embryos. For this reason, we recommend using darkness to induce $\mathrm{SE}$ in this species.

In the SE system, a significant explant response to sucrose and mineral salts concentration was observed. The optimal concentration of sucrose for production of $C$. delgadii somatic embryos was only $1 \%$, whereas $5 \%$ sucrose had an inhibitory effect. In the epiphytic fern $\mathrm{Mi}$ crogramma vacciniifolia, $4 \%$ sucrose resulted in an increase in the number of sporophytic regenerants per leaf explant (Hirsch 1975). Media supplemented with 2-3\% sucrose or glucose is also optimal for apogamous sporophyte production in many fern species (Whittier and Steeves 1960; Fernández et al. 1996; Cordle et al. 2007; Bui et al. 2012). Conversely, apogamy in Pityrogramma calomelanos and Equisetum arvense was favored by the absence of sucrose and a reduction in the concentration of mineral salts-from $1 / 2 \mathrm{MS}$ to $1 / 10$ or $1 / 80 \mathrm{MS}$ (Kuriyama et al. 1989; Martin et al. 2006). Similarly, Fernández et al. (1999) showed a significant increase in sporophyte formation in Osmunda regalis and Pteris ensiformis when their gametophytes were cultured in the absence of nutrients (water $+0.7 \%$ agar) for 2 months. However, for Ceratopteris richardii, a low sugar concentration of $0.5 \%$ favors apospory over regeneration (Cordle et al. 2007; Bui et al. 2012). Our study showed that even for plain agar gel, 
$13.9 \%$ of $C$. delgadii explants demonstrated embryogenic competency when cultured under photoperiod conditions. It is very difficult to find similar examples of SE induction among spermatophytes. In seed plants, there are only individual examples of species in which SE can be controlled by the non-osmotic effects of sucrose. A sucrose concentration of 2-3\%, had a highly significant effect on SE induction in Linum usitstissimum and Cucumis melo (Cunha and Fernandes-Ferreira 1999; Gray et al. 1993). Media supplemented with greater sucrose concentrations (i.e. 4 or $6 \%$ ) appeared to inhibit the induction and the development of somatic embryos in these species. For Dianthus caryophyllus, Cucumis melo cv. 'Shimoshirazu', as well as other spermatophytes, changes in the osmotic pressure of the medium were required in order to increase the number of embryos (Karami et al. 2006; Lou and Kako 1995).

\section{Factors regulating somatic embryo and sporophyte development}

The results reported here show that the investigated factors, i.e. light, sucrose and mineral salt concentration, affect both somatic embryo and sporophyte development.

The somatic embryos of $C$. delgadii passed through the linear and early embryonic leaf stages (Mikuła et al. 2015), but leaf development was inhibited if they were induced and constantly maintained on plain agar gel in the dark. Light promoted somatic embryo development as far as the late embryonic leaf stage, whereas the presence of both light and sucrose was necessary to develop an embryonic leaf and root. Our results are consistent with those obtained by Tavares and Sussex (1968) when researching etiolated leaves of Todea barbara. They were the first to show that only two factors are required to achieve maximum surface area growth in cultured leaf blades. However, later growth of juvenile sporophytes needed the presence of mineral salts when using MS medium.

Our results also confirmed that light plays a pivotal role in the growth of somatic embryo-derived sporophytes. Dark-grown sporophytes exhibited arrested growth of the leaf blade, a longer stipe, greater spacing between the fronds (internodes), and the inhibition of root growth. Tavares and Sussex (1968) showed that when etiolated sporophytes of Todea barbara are returned to light, deetiolation permits resumed leaf blade growth and differentiation.

The second important factor for fern sporophyte development is sucrose (Whittier and Steeves 1960; Dykeman and Cumming 1985; Fernández et al. 1996; AmbrožičDolinšek and Camloh 1997). A high concentration of sucrose (more than $2 \%$ ) resulted in the shortening of the stipe and the thickening of fronds, as well as an increase in both the number and size of roots in $C$. delgadii. Our results are consistent with data obtained for Matteuccia struthiopteris and Platycerium bifurcatum (Dykeman and Cumming 1985; Ambrožič-Dolinšek and Camloh 1997). An increase in sucrose concentration resulted in a greater number of roots in cultures of these species. The optimal sucrose concentration for root formation in M. struthiopteris (Dykeman and Cumming 1985), P. bifurcatum (Ambrožič-Dolinšek and Camloh 1997) and C. delgadii was $0.75 \%, 1$ and $2 \%$, respectively. For P. bifurcatum and $C$. delgadii, spontaneous rooting was displayed by in vitrogrown propagules and somatic embryos (Liao and $\mathrm{Wu}$ 2011; Mikuła et al. 2015). It is worth emphasizing that like seed plants (Gaj 2004), an embryonic root primordium forms in accordance with previous studies (Mikuła et al. 2015), but root development in vitro is strongly dependent on physical and chemical factors.

Mineral salt concentration is the third factor that has been associated with greater frequency of abnormal regenerated fern sporophytes. In Dryopteris affinis ssp. affinis, full-strength MS medium favored sporophyte development (Fernandez et al. 1996). Our study showed the necessity of using half-strength MS medium to stimulate normal development of $C$. delgadii sporophytes. The results reported here highlight the importance of mineral salt concentration in the development of juvenile sporophytes.

\section{Conclusions}

This is the first report to define the culture conditions necessary to induce SE in ferns growing in vitro, and the first to show that etiolation plays a critical role in this process. The results of this study demonstrate that initiation of the embryogenic pathway in $C$. delgadii is independent of exogenous plant growth regulators, and can be effectively stimulated by the presence of sucrose or mineral salts. Moreover, light is one of the most important external factors which affects both the type of morphogenetic response and sporophyte development. The system described here is the first to investigate the factors responsible for the transition of fern somatic cells to embryogenic cells. It provides an excellent model for the study of endogenous hormonal regulation of plant embryogenesis and fern sporophyte development. This protocol could also be used to facilitate the rapid propagation and conservation of the tree fern $C$. delgadii.

Acknowledgments This research was supported by the Polish National Center for Science (NCN), No. 2011/03/B/NZ9/02472.

Author contribution The authors have made the following declarations regarding their contributions: Conceived and designed the 
experiments: AM. Performed the experiments: MP, MG. Analyzed the data: AM, MP, MG. Contributed reagents/materials/analysis tools: AM. Contributed to the writing of the manuscript: AM, JJR.

\section{Compliance with ethical standards}

Conflict of interest The authors declare that they have no conflict of interest.

Open Access This article is distributed under the terms of the Creative Commons Attribution 4.0 International License (http://crea tivecommons.org/licenses/by/4.0/), which permits unrestricted use, distribution, and reproduction in any medium, provided you give appropriate credit to the original author(s) and the source, provide a link to the Creative Commons license, and indicate if changes were made.

\section{References}

Akula A, Becker D, Bateson M (2000) High-yielding repetitive somatic embryogenesis and plant recovery in a selected tea clone, 'TRI-2025', by temporary immersion. Plant Cell Rep 19:1140-1145

Ambrósio ST, de Melo NF (2004) Interaction between sucrose and $\mathrm{pH}$ during in vitro culture of Nephrolepis biserrata (Sw.) Schott (Pteridophyta). Acta Bot Bras 18:809-813

Ambrožič-Dolinšek J, Camloh M (1997) Gametophytic and sporophytic regeneration from bud scales of the fern Platycerium bifurcatum (Cav.) C. Chr. in vitro. Ann Bot 80:23-28

Bharati SK, Manabendra DC, Behari MP (2013) In vitro propagation in Pteridophytes: a review. Int J Res Ayurveda Pharm 4:297-303

Bui LT, Hurst A, Irish EE, Cheng CL (2012) The effects of sugars and ethylene on apospory and regeneration in Ceratopteris richardii. Am J Plant Sci 3:953-961

Chen J-T, Chang W-C (2002) Effects of tissue culture conditions and explant characteristics on direct somatic embryogenesis in Oncidium 'Gower Ramsey'. Plant Cell Tissue Organ Cult 69:41-44

Cordle AR, Irish EE, Cheng C-L (2007) Apogamy induction in Ceratopteris richardii. Int J Plant Sci 168:361-369

Cordle AR, Bui LT, Irish EE, Cheng CL (2011) Laboratory-induced apogamy and apospory in Ceratopteris richardii. In: Fernández H, Kumar A, Revilla MA (eds) Working with Ferns: issues and applications. Springer Science + Business Media, LLC, Berlin, pp 25-36

Cunha A, Fernandes-Ferreira M (1999) Influence of medium parameters on somatic embryogenesis from hypocotyls explants of flax (Linum usitatissimum L.). J Plant Physiol 155:591-597

Dykeman BW, Cumming BG (1985) In vitro propagation of the Ostrich fern (Matteuccia struthiopteris). Can J Plant Sci 65:1025-1032

Fernández H, Revilla MA (2003) In vitro culture of ornamental ferns. Plant Cell Tissue Organ Cult 73:1-13

Fernández H, Bertrand AM, Sánchez-Tamés R (1996) Influence of tissue culture conditions on apogamy in Driopteris affinis sp. affinis. Plant Cell Tissue Organ Cult 45:93-97

Fernández H, Bertrand AM, Sánchez-Tamés R (1999) Biological and nutritional aspects involved in fern multiplication. Plant Cell Tissue Organ Cult 56:211-214

Ferreira DAT, Sattler MC, Carvalho CR, Clarindo WR (2015) Embryogenic potential of immature zygotic embryos of Passiflora: a new advance for in vitro propagation without plant growth regulators. Plant Cell Tissue Organ Cult. doi:10.1007/ s11240-015-0796-1
Filonova LH, Bozhkov PV, von Arnold S (2000) Developmental pathway of somatic embryogenesis in Picea abies as revealed by time-lapse tracking. J Exp Bot 51:249-264

Gaj M (2004) Factors influencing somatic embryogenesis induction and plant regeneration with particular reference to Arabidopsis thaliana (L.) Heynh. Plant Growth Reg 43:27-47

Gow W-P, Chen J-T, Chang W-C (2010) Enhancement of direct somatic embryogenesis and plantlet growth from leaf explants of Phalaenopsis by adjusting culture period and explant length. Acta Physiol Plant 32:621-627

Gray DJ, McColley DW, Compton ME (1993) High-frequency somatic embryogenesis from quiescent seed cotyledons of Cucumis melo cultivars. J Am Soc Hort Sci 118:425-432

Hirsch AM (1975) The effect of sucrose on the differentiation of excised fern leaf tissue into either gametophytes or sporophytes. Plant Physiol 56:390-393

Hirsch AM (1976) The development of aposporous gametophytes and regenerated sporophytes from epidermal cells of excised fern leaves: an anatomical study. Am J Bot 63:263-271

Jiménez VM (2005) Involvement of plant hormones and plant growth regulators on in vitro somatic embryogenesis. Plant Growth Reg 47:91-110

Kamada H, Kobayashi K, Kiyosue T, Harada H (1989) Stress induced somatic embryogenesis in carrot and its application to synthetic seed production. In Vitro Cell Dev Biol 25:1163-1166

Kamada H, Ishikawa K, Saga H, Harada H (1993) Induction of somatic embryogenesis in carrot by osmotic stress. Plant Tissue Cult Lett 10:38-44

Karami O, Deljou A, Esna-Ashari M, Ostad-Ahmadi P (2006) Effect of sucrose concentrations on somatic embryogenesis in carnation (Dianthus caryophyllus L.). Sci Hortic 110:340-344

Kuriyama A, Hojoh T, Sugawara Y, Matsushima H, Takeuchi M (1989) A method for the rapid growth in culture of gametophytes of Equisetum arvense with antheridia. Plant Cell Physiol 30:1189-1192

Kuriyama A, Kobayashi T, Maeda M (2004) Production of sporophytic plants of Cyathea lepifera, a tree fern, from in vitro cultured gametophyte. J Jpn Soc Hortic Sci 73:140-142

Liao YK, Wu YH (2011) In vitro propagation of Platycerium bifurcatum (Cav.) C. Chr. via green globular body initiation. Bot Stud 52:455-463

Lou H, Kako S (1995) Role of high sugar concentrations in inducing somatic embryogenesis from cucumber cotyledons. Sci Hortic 64:11-20

Mahdavi-Darvari F, Mohd Noor N, Ismanizan I (2015) Epigenetic regulation and gene markers as signals of early somatic embryogenesis. Plant Cell Tissue Organ Cult 120:407-422

Martin KP, Sini S, Zhang C-L, Slater A, Madhusoodanan PV (2006) Efficient induction of apospory and apogamy in vitro in silver fern (Pityrogramma calomelanos L.). Plant Cell Rep 25:1300-1307

Materi DM, Cumming BG (1991) Effect of carbohydrate deprivation on rejuvenation, apospory, and regeneration in ostrich fern (Matteuccia struthiopteris) sporophytes. Can J Bot 69:1241-1245

Menéndez V, Villacorta NF, Revilla MA, Gotor V, Bernard P, Fernández H (2006) Exogenous and endogenous growth regulators on apogamy in Dryopteris affinis (Lowe) Fraser-Jenkins sp. affinis. Plant Cell Rep 25:85-91

Mikuła A, Pożoga M, Tomiczak K, Rybczyński J (2015) Somatic embryogenesis in ferns: a new experimental system. Plant Cell Rep 34:783-794

Moura IR, Simões-Costa MC, Garcia J, Silva MJ, Duarte MC (2012) In vitro culture of tree fern spores from Cyatheaceae and Dicksoniaceae families. Acta Hortic 937:455-461

Murashige T, Skoog F (1962) A revised medium for rapid growth and bioassays with tobacco tissue cultures. Physiol Plant 15:473-497 
Nakagawa H, Saijyo T, Yamauchi N, Shigyo M, Kako S, Ito A (2001) Effect of sugars and abscisic acid on somatic embryogenesis from melo (Cucumis melo L.) expanded cotyledon. Sci Hortic 90:85-92

Nhut DT, Le BV, Fukai S, Tanaka M, Van KTT (2001) Effect of activated charcoal, explant size, explant position and sucrose concentration on plant and shoot regeneration of Lilium longiflorum via young stem culture. Plant Growth Reg 33:59-65

Parajuli J, Joshi SD (2014) In vitro study of effects of growth hormones on sporophyte development of Cyathea spinulosa. Int J Biodivers Conserv 6:247-255

Pinto G, Park Y-S, Silva S, Neves L, Araújo C, Santos C (2008) Factors affecting maintenance, proliferation, and germination of secondary somatic embryos of Eucalyptus globulus Labill. Plant Cell Tissue Org Cult 95:69-78

Raemakers CJJM, Jacobsen E, Visser RGF (1995) Secondary somatic embryogenesis and applications in plant breeding. Euphytica 81:93-107

Raghavan V (1989) Developmental biology of fern gametophytes. Cambridge University Press, Cambridge, pp 259-295

Rashid A (2009) An introduction to bryophyta: diversity, development and differentiation. In: Chapter 11: alternation of generations. VIKAS Publishing House PVT LTD, New Delhi, pp 237-249

Rybczyński J, Mikuła A (2011) Tree ferns biotechnology: from spores to sporophytes. In: Fernández H, Kumar A, Revilla MA (eds) Working with Ferns: issues and applications. Springer Science + Business Media, New York, Dordrecht, Heidelberg, London, pp 135-147

Smith DL, Krikorian AD (1990) Somatic proembryo production from excised, wounded zygotic carrot embryo on hormone-free medium: evaluation of the effect of $\mathrm{pH}$, ethylene and activated charcoal. Plant Cell Rep 9:34-37

Somer A, Arbesú R, Menéndez V, Revilla MA, Fernández H (2010) Sporophyte induction studies in ferns in vitro. Euphytica 171:203-210

Takamura T, Tanaka M (1996) Somatic embryogenesis from the etiolated petiole of cyclamen (Cyclamen persicum Mill.). Plant Tissue Lett 13:43-48

Tavares JE, Sussex IM (1968) Expansion growth of isolated leaf blades of Todea barbara. Planta 80:113-128

White RA (1971) Experimental and developmental studies of the fern sporophyte. Bot Rev 37:509-540

Whittier DP, Pratt LH (1971) The effect of light quality on the induction of apogamy in prothalli of Pteridium aquilinum. Planta 99:174-178

Whittier DP, Steeves TA (1960) The induction of apogamy in the bracken fern. Can J Bot 38:925-930

Yang X, Zhang X (2010) Regulation of somatic embryogenesis in higher plants. Crit Rev Plant Sci 29:36-57

Yan-Lin S, Soon-Kwan H (2012) Recent advances of in vitro embryogenesis of monocotyledon and dicotyledon. In: Ken-Ichi Sato (ed) Embryogenesis. ISBN: 978-953-51-0466-7, InTech. http://www.intechopen.com/books/embryogenesis/recent-advanc es-of-invitro-embryogenesis-of-monocotyledon-and-dicotyledon

Zavattieri MA, Frederico AM, Lima M, Sabino R, Arnholdt-Schmitt B (2010) Induction of somatic embryogenesis as an example of stress-related plant reactions. Electron J Biotech 13. http://www. ejbiotechnology.cl/content/vol13/issue1/full/4/ 